\title{
Thermal analysis of $\mathrm{SmTiFe}_{11-x} \mathrm{Co}_{x}(x=0,11)$ and $\mathrm{DyTiCo}_{11}$ intermetallic alloys
}

\author{
B.G. Demczyk \\ North Campus Electron Microbeam Analysis Laboratory, Department of Materials Science and Engineering, \\ The University of Michigan, Ann Arbor, MI 48109-2143, USA
}

Received 30 June 1992

\begin{abstract}
Alluys of composition $\mathrm{SmTiFe}_{11-x} \mathrm{Co}_{x}(x=0,11)$ and $\mathrm{DyTiCo}_{11}$ have been examined via differential thermal analysis. Thermal peaks found in the Sm-containing $\mathrm{TiFe}_{11}$ sample were consistent with a 1-12 phase, with additional $\mathrm{Fe}_{2} \mathrm{Ti}$ and $\alpha-\mathrm{Fe}$ phases present, as found in a previous work. In $\mathrm{SmTiCo}_{11}$, evidence for a 1-12, a 2-17 and a primarily Co-containing solid solution was found. When Dy is substituted for $\mathrm{Sm}$ in the $\mathrm{Co}_{11}$ sample, an additional peak, possibly due to the formation of the hexagonal 2-17 phase from the rhombohedral phase was noted. In addition, peaks corresponding to the ferromagnetic ordering of Fe in $\mathrm{SmTiFe}_{11}$ and of Co in DyTiCo ${ }_{11}$ were observed.
\end{abstract}

\section{Introduction}

Among permanent magnets, the $\mathrm{Nd}_{2} \mathrm{Fe}_{14}$ B-based magnets have the highest energy product (in excess of $45 \mathrm{MGOe}$ ). However, their Curie temperatures are relatively low, leading to a large temperature coefficient of coercivity that limits the range of their application. Also, corrosion is a problem for these magnets. Ohashi et al. [1] and Stadelmaier et al. [2] have reported a body-centered tetragonal $\mathrm{SmTiFe}_{11}$ compound which is isomorphous with $\mathrm{ThMn}_{12}$ (I4/ $\mathrm{mmm})$. This material has solicited interest due to its high room-temperature anisotropy field ( $>100 \mathrm{kOe}$ ) which renders it a promising candidate for permanent magnet applications. The Curie temperature of this material $\left(\approx 300^{\circ} \mathrm{C}\right)$ is comparable to that of $\mathrm{Nd}_{2} \mathrm{Fe}_{14} \mathrm{~B}$ and can be increased by replacing $\mathrm{Fe}$ with Co. Therefore, it is of interest to examine the effects of Co substitution on the phase distribution in the $\mathrm{SmTiFe} \mathrm{H}_{1}$ alloy. Also, the effect of replacing $\mathrm{Sm}$ by other rare earth atoms $(R)$ is of interest. The magnetic properties, phase and structural characteristics in the $\mathrm{RTiFe}_{11-x} \mathrm{Co}_{x}$ system have been examined previously [3-9]. The results of phase analysis using scanning electron microscopy [8] indicate the presence of $\mathrm{a}_{2}(\mathrm{Fe}, \mathrm{Co}, \mathrm{Ti})_{17}$ phase and a $(\mathrm{Fe}, \mathrm{Co}, \mathrm{Ti})$ solid solution in addition to the $\mathrm{R}(\mathrm{Fe}, \mathrm{Co}, \mathrm{Ti})_{12}$ phase with increasing Co content in samples annealed at $1000^{\circ} \mathrm{C}$. The reported phase diagrams for these ternary systems are incomplete (see, for example, ref. [10]). Prior transmission electron microscopy/X-ray energy dispersive spectroscopy analyses have identified the predominant phases in these alloys [11]. In this work, the specific transition temperature regimes in the bulk alloys $\mathrm{SmTiFe}_{11}$, $\mathrm{SmTiCo}_{11}$ and $\mathrm{DyTiCo}_{11}$ were examined by differential thermal analysis.

\section{Experimental}

Samples with the compositions of $\mathrm{SmTiFe}_{11}$, $\mathrm{SmTiCo}_{11}$ and $\mathrm{DyTiCo}_{11}$ were prepared from highpurity constituent elements by induction melting in a $450 \mathrm{kHz}$ water-cooled copper boat furnace in flowing argon. Excess samarium was added to compensate for samarium loss during melting. As-cast ingots were wrapped in Ta foils, sealed in argon filled quartz tubes and annealed at $1000^{\circ} \mathrm{C}$ for one week. Samples were then broken into approximately $3 \mathrm{~mm}$ diameter chunks for analysis. Thermal analysis was performed using a Perkin-Elmer DTA 1700 differential thermal analyzer coupled to a System $7 / 4$ thermal analysis controller. Heating and cooling scans 
were taken at $10^{\circ} / \mathrm{min}$ for 200 to $1450^{\circ} \mathrm{C}$. The sample was kept in an isothermal state between heating and cooling runs.

\section{Results and discussion}

Figs. $1 \mathrm{a}$ and $1 \mathrm{~b}$ represent heating and cooling curves, respectively, for the $\mathrm{SmTiFe}_{11}$ alloy. From fig. 1a, we observe peaks at approximately 1260 and $1310^{\circ} \mathrm{C}$. The higher-temperature peak is most likely due to the decomposition of the $\mathrm{Fe}_{2} \mathrm{Ti}$ phase into an Fe-Ti solid solution and possibly $\alpha-F e[12,13]$. All three phases have been found in previous transmission electron microscopy/X-ray energy dispersive spectroscopy analyses [11]. In that work, the reported stoichiometries were $75 \% \mathrm{Fe}-25 \%$ Co for the $\mathrm{Fc}_{2} \mathrm{Ti}$ and $98 \% \mathrm{Fe}-2 \% \mathrm{Ti}$ for the solid solution. The
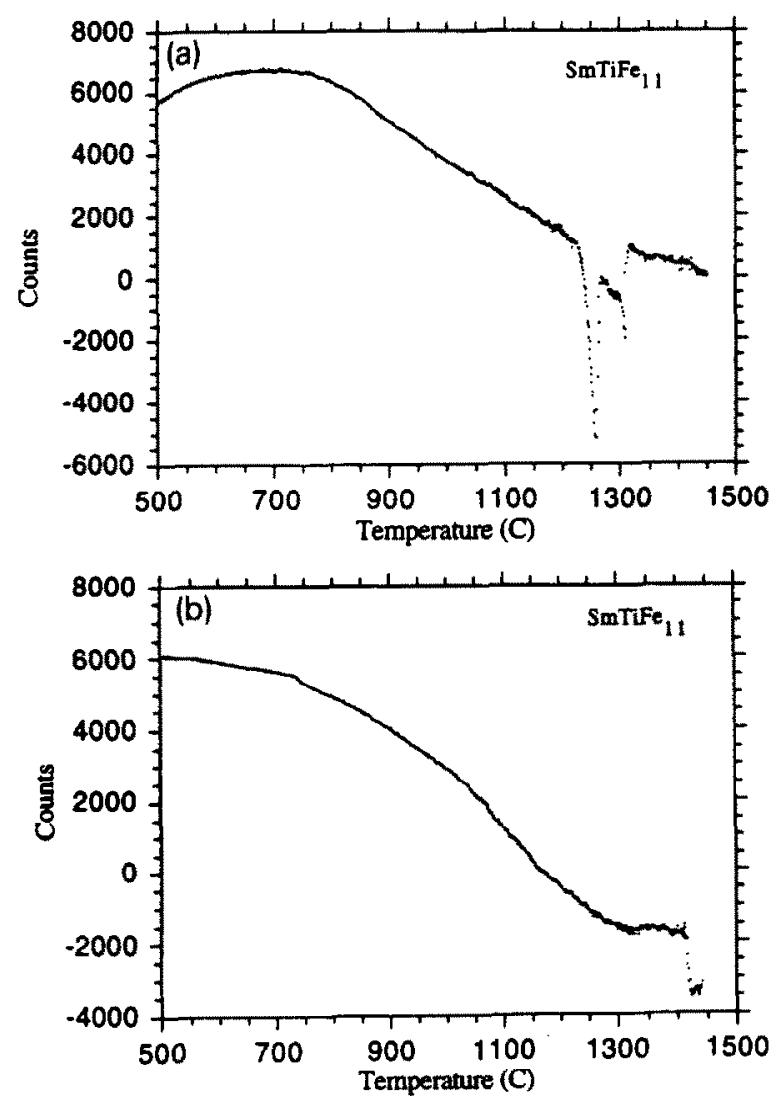

Fig. 1. (a) Heating and (b) cooling curves for $S m T i F e_{11}$ alloy. peak at $1260^{\circ} \mathrm{C}$ is most likely due to the decomposition of a "1-12" phase, which is not identified as such in ref. [12], but was nevertheless found in ref. [11]. In this case the stoichiometry was $85 \% \mathrm{Fe}-8 \%$ $\mathrm{Sm}-7 \% \mathrm{Ti}$. Upon cooling from an isothermal state at $1450^{\circ} \mathrm{C}$, two peaks appear at 1440 and $1410^{\circ} \mathrm{C}$, respectively. The upper peak is due to the formation of $\mathrm{Fe}_{2} \mathrm{Ti}$, which congruently melts [13]. The lower peak extends over a range of temperatures, down to $1350^{\circ} \mathrm{C}$, which is consistent with the published phase diagram [13]. Close examination of fig. $1 \mathrm{~b}$ reveals a small peak at $747^{\circ} \mathrm{C}$, which represents the ferromagnetic ordering of Fe [13].

Figs. $2 a$ and $2 b$ depict the same curves for the $\mathrm{SmTiCo}_{11}$ alloy. From fig. $2 \mathrm{a}$, we again note the presence of two peaks. These most likely correspond to the breakdown of the $1-12\left(1210^{\circ} \mathrm{C}\right)$ and the 2$17\left(1250^{\circ} \mathrm{C}\right)$ phases. It should be noted that there is no explicit 1-12 phase shown in ref. [14], but this
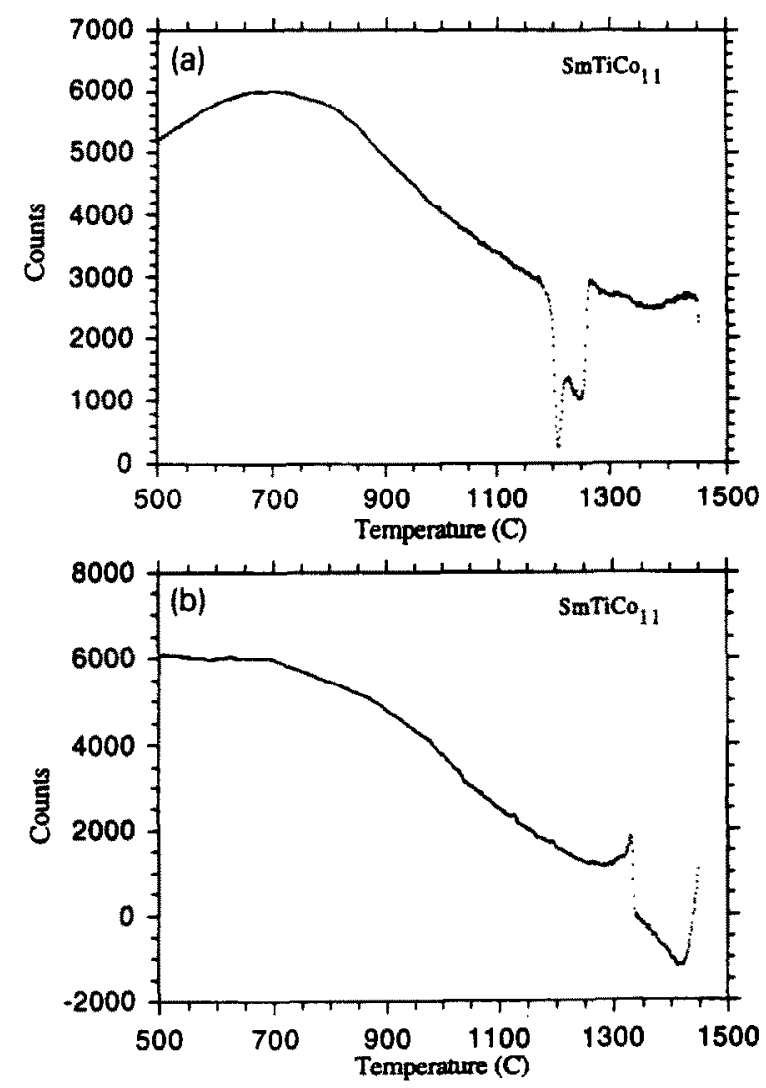

Fig. 2. (a) Heating and (b) cooling curves for $\mathrm{SmTiCo}_{11}$ alloy. 
phase $(84 \% \mathrm{Co}-7 \% \mathrm{Sm}-9 \% \mathrm{Ti})$ was found in ref. [11], along with the $2-17$ phase $(85 \% \mathrm{Co}-9.5 \% \mathrm{Sm}-$ $5 \% \mathrm{Ti})$. The highest-temperature peak $\left(\approx 1450^{\circ} \mathrm{C}\right)$ is that of the melting of near-elemental $\mathrm{Co}[13]$, which has also been found as a solid solution $(90 \%$ Co-10\% $\mathrm{Ti}$ ) in a previous work [11]. The cooling curve (fig. 2b) displays a primary peak at $1340^{\circ} \mathrm{C}$. However, it is extended over a range of 1250 $1340^{\circ} \mathrm{C}$, encompassing the reformation of the $2-17$ and 1-12 intermetallic phases. We also observe the solidification of $\mathrm{Co}$ at $1450^{\circ} \mathrm{C}$.

When $\mathrm{Sm}$ is replaced by Dy, we obtain qualitatively similar heating/cooling curves to the Sm case (figs. $3 a$ and $3 b$ ). Thus we see peaks at 1210 and $1250^{\circ} \mathrm{C}$ corresponding to the $1-12$ and $2-17$ phases, respectively. Again, no $1-12$ phase is depicted in ref. [15], but such was found in ref. [11] $(84.5 \% \mathrm{Co}-$ $8 \% \mathrm{Dy}-7.5 \% \mathrm{Ti})$, in addition to $2-17(85.5 \% \mathrm{Co}-$ $10 \% \mathrm{Dy}-4.5 \% \mathrm{Ti})$. Also, there is seen to be an ex-
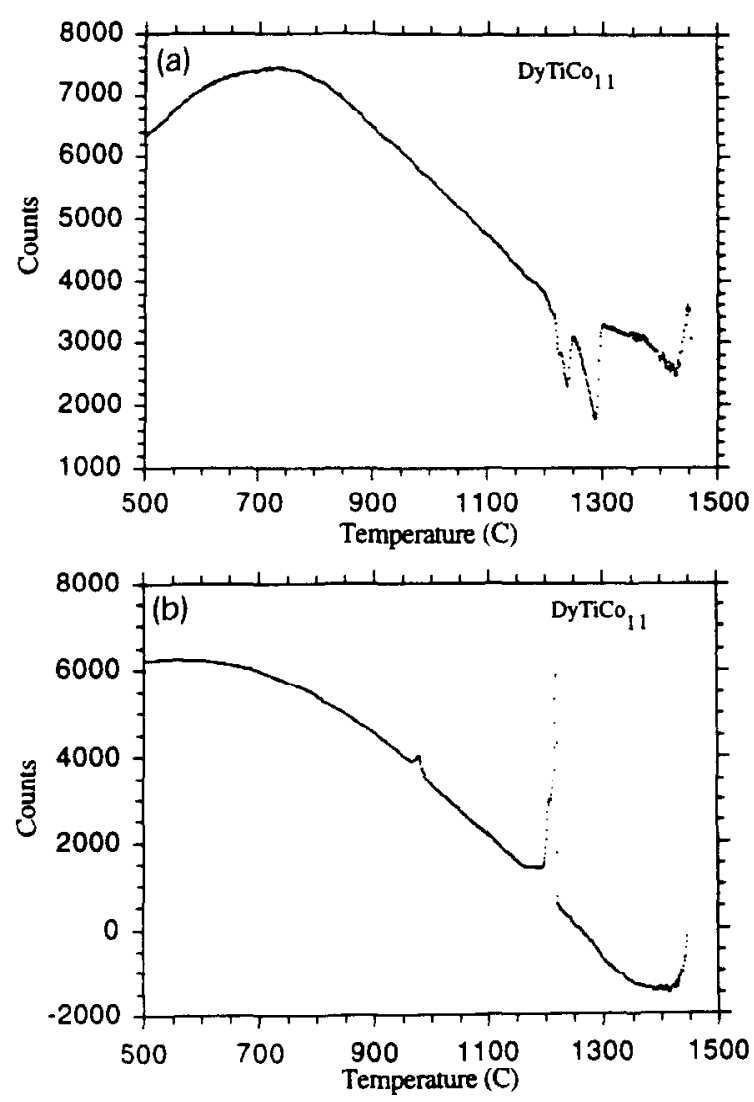

Fig. 3. (a) Heating and (b) cooling curves for $\mathrm{DyTiCo}_{11}$ alloy. tended melting regime $\left(\approx 1350-1430^{\circ} \mathrm{C}\right)$, possibly corresponding to the partial transformation of the rhombohedral 2-17 form to the hexagonal form, which was reported in ref. [11]. As in the Sm case, near-elemental $\mathrm{Co}$ is seen to melt at $\approx 1450^{\circ} \mathrm{C}$.

The cooling curve (fig. $3 \mathrm{~b}$ ) is considerably simpler, exhibiting only the Co peak at $1450^{\circ} \mathrm{C}$, and a sharp peak at $1225^{\circ} \mathrm{C}$, due to the formation of one "2-17" phase, with stoichiometry 24\% Dy + Ti, 76\% $\mathrm{Co}$, as depicted in ref. [15]. Close examination of fig. $3 \mathrm{~b}$ also reveals a small peak at $\approx 960^{\circ} \mathrm{C}$, which corresponds to the ferromagnetic ordering of $\mathrm{Co}$, as shown in ref. [13].

\section{Summary}

Alloys of the composition $\mathrm{SmTiFe}_{11}, \mathrm{SmTiCo}_{11}$ and $\mathrm{DyTiCo}_{11}$ have been examined by differential thermal analysis. Thermal peaks found in the Smcontaining $\mathrm{TiFe}_{11}$ sample were consistent with a 112 phase, with additional $\mathrm{Fe}_{2} \mathrm{Ti}$ and $\alpha-\mathrm{Fe}$ phases present, as found in a previous work. In $\mathrm{SmTiCo}_{11}$, evidence for a 1-12, a 2-17 and a primarily Co-containing solid solution was found. When Dy is substituted for $\mathrm{Sm}$ in the $\mathrm{Co}_{11}$ sample, an additional peak, possibly due to the formation of the hexagonal 2-17 phase from the rhombohedral phase was found. In addition, peaks corresponding to the ferromagnetic ordering of $\mathrm{Fe}$ in $\mathrm{SmTiFe}_{11}$ and of $\mathrm{Co}$ in DyTiCo $_{11}$ were observed.

\section{Acknowledgement}

Samples were supplied by the Advanced Materials Corporation, Pittsburgh, PA.

\section{References}

[1] K. Ohashi, Y. Tawara, R. Osugi, J. Sakurai and Y. Komura, J. Less-Common Metals 139 (1988) L1.

[2] H.H. Stadelmaier, F.J. Cadieu and N.C. Liu, Mater. Letters 6 (1988) 80

[3] S.F. Cheng, V.K. Sinha, Y. Xu, J.M. Elbicki, W.E. Laughlin, S.G. Sankar and D.E. Laughlin, J. Mag. Magn. Mater. 75 (1988) 330 . 
[4] E.B. Boltich, B.M. Ma, L.Y. Zhang, F. Pouranian, S.K. Malik, S.G. Sankar and W.E. Wallace, J. Mag. Magn. Mater. 78 (1989) 364.

[5] V.K. Sinha, S.K. Malik, D.T. Adroja, J.M. Elbicki, S.G. Sankar and W.E. Wallace, J. Mag. Magn. Mater. 80 (1989) 281.

[6] L.Y. Zhang, E.B. Boltich, V.K. Sinha and W.E. Wallace, IEEE Trans. Magn. 25 (1989) 3303.

[7] V.K. Sinha, S.F. Cheng, W.E. Wallace and S.G. Sankar, J. Mag. Magn. Mater. 81 (1989) 227.

[8] S.F. Cheng, V.K. Sinha, B.G. Demczyk, W.E. Wallace and D.E. Laughlin, unpublished research,

[9] S.F. Cheng, V.K. Sinha, Y. Xu and W.E. Wallace, unpublished research.
[10] T. Massalski, ed., Binary alloy phase diagrams, 2nd Ed. (ASM International, Materials Park, OH, 1990).

[11] S.F. Cheng, B.G. Demczyk and D.E. Laughlin, J. Mag. Magn. Mater. 84 (1990) 162.

[12] O. Kubashewski, Iron binary phase diagram (Springer, Berlin, 1982) p. 105.

[13] J.L. Murray, Phase diagrams of binary titanium alloys (ASM International, Materials Park, $\mathrm{OH}, 1987$ ).

[14] W.G. Moffatt, ed., Handbook of binary alloy phase diagrams (General Electric Corporation, Schenectedy, NY, 1981).

[15] T. Massalski, in: Binary alloy phase diagrams, 2nd Ed., ed. T. Massalski (ASM International, Materials Park, OH, 1990) p. 1184. 